\title{
ENSINO PÚBLICO E ACESSO AO ENSINO SUPERIOR: A QUESTÃO DAS COTAS
}

\author{
Danielle Costa Maia* \\ Débora Vieira Dos Santos** \\ Gustavo Henrique Cavalcante Marques*** \\ Iliane Rodrigues Rego Brasil**** \\ Lucas Carvalho Macedo ${ }^{* * * * *}$ \\ Stéphanye Lima Araújo****** \\ Orientador: José Vilmar da Silva ${ }^{* * * * * *}$
}

\section{RESUMO}

O presente artigo tem por objetivo tratar sobre o ensino público, bem como o acesso ao ensino superior, além de uma abordagem sobre a questão da adoção de medidas de cotas raciais e para pessoas de baixa renda. Para tanto, será exposto uma análise sobre a condição em que o ensino público se encontra, bem como as consequências dos quais a adoção de contas geram.

Palavras-chave: Ensino Público. Acesso à Educação. Ensino Superior. Cotas raciais. Cotas para pessoas de baixa renda. Desigualdade.

* Academica de Direito da Universidade Metodista de São Paulo. Tesoureira na Academia de Direito do ABC.

**Academica de Direito da Universidade Medotista de São Paulo. Primeira Secretária da Academia de Direito do ABC.

*** Academico de Direito da Universidade Metodista de São Paulo. Pesquisador PIBIC. Presidente da Academia de Direito do ABC.

**** Academica de Direito da Universidade Metodista de São Paulo.

$* * * * *$ Academico de Direito da Universidade Metodista de São Paulo, membro fundador da Academia de Direito do ABC.

****** Academico de Direito da Universidade Metodista de São Paulo. Segunda Secretária da Academia de Direito do ABC.

$* * * * * * *$ Mestre em Direitos Humanos da Criança e do Adolescente pela Universidade Bandeirante de São Paulo - UNIBAN. Especialista em Direito Civil pela Faculdade de Direito de São Bernardo do Campo - FDSBC. Advogado. Professor Universitário. 
PUBLIC EDUCATION AND ACCESS TO HIGHER EDUCATION: A QUESTION OF QUOTAS

\begin{abstract}
This article aims to address on public education and access to higher education, and an approach to the question of the adoption of racial quotas and measures for low-income people. For this, an analysis of the condition in which public education is will be exposed, and the consequences which the adoption of accounts generate.
\end{abstract}

Key words: Public education. Access to Education. Higher education. Racial quotas. Quotas for low-income people. Inequality.

\title{
INTRODUÇÃO
}

A sociedade é formada por pilares de sustentação, esses pilares devem estar erguidos em bases firmes e concretas para que a sociedade possa se desenvolver, sendo a educação a base fundamental que dá a solidez necessária para que isso ocorra.

A educação é um direito social previsto no artigo $6^{\circ}$ da Constituição amparado pelos artigos 205 e seguintes, onde é estabelecido que a educação é um direito de todos e dever do Estado e da família, em conjunto com colaboração da sociedade, visando o pleno desenvolvimento da pessoa, seu preparo para o exercicio da cidadania e a sua qualificação para o trabalho.

O questionamento que se faz, é se o Estado Brasileiro, por meio de seus mecanismos governamentais, tem de fato cumprido com eficácia os deveres a ele inerentes no campo educacional por intermédio dos mandamentos constitucionais.

De fato, há mecanismos da administração Públicaque visam dar acesso à educação, mas será que estes mecanismos realmente garantem acesso à todos, sem quaisquer distinções, conforme preconiza o caput do artigo $5^{\circ}$ da Constituição Federal?

É claro as pessoas não são iguais, cada qual possui vantagens ou encontram-se em situação de vulnerabilidade. O princípio da isonomia consiste em tratar os diferentes de 
forma diferente para que todos tenham igualdade de acesso e garantia de direitos.

Ocorre que se alguns são tratados diferente exatamente no que se refere ao acesso, então não há o que se falar em igualdade.

Sabe-se que há cotas para negros e indíos ao acesso ao ensino superior, porém tais medidas não garantem a igualdade de possibilidades destes sujeitos ao ensino superior, na verdade o efeito é diverso, pois estes individuos possuem vantagem sobre os demais concorrentes à uma vaga na Universidade ou faculdade.

As cotas só garantiriam igualdade, se estes indivíduos apresentassem alguma dificuldade fisiológica intelectual que os colocassem em desvantagem às demais pessoas que concorrem a mesma vaga, o que não é verdade, já que negros e índios não são diferentes que brancos, asiáticos, pardos, anões, cristãos, judeus, paquistaneses ou seja lá o que for.

Não há qualquer fator que indique esta desvantagem no qual justificaria a implementação de cotas para esses individuos, a não ser uma desvantagem histórica e cheia de preconceitos, porém nada disso afeta o acesso destes indiviuos ao esino superior. Ao contrário, essa distinção apenas demonstra o preconceito que nossas leis ainda herdam.

\section{DIREITO À EDUCAÇÃO (ASPECTOS JURÍDICOS)}

$\mathrm{O}$ direito à educação é sem dúvida uma preocupação do Estado, isto porque, seu papel é garantir aos cidadãos o bem comum ${ }^{1}$ Para tanto, foi criado o direito positivado (escrito), que regulamenta os acordos sociais firmados, estabelecendo, obrigações, restrições e previsão de procedimentos, na forma de lei.

\footnotetext{
Moura, Daiana Malheiros de. A EFETIVAÇÃO DOS DIREITOS FUNDAMENTAIS PELO ESTADO FISCAL: FUNÇÃO SOCIAL DOS TRIBUTOS. 2011. Disponível por meio do site < http://www.unisc.br/portal/images/stories/mestrado/direito/dissertacoes/2011/daianamalheiros.pdf> Acesso em 05/06/2017.
} 
A lei máxima de um país é sua Constituição, na qual é suprema diante as leis infraconstitucionais do territorio Nacional. Nas palavras de Vicente Paulo e Marcelo Alexandrino $^{2}$ "a Constituição é simplesmente a forma de organização do Estado".

Além disso, a Constituição visa estabelecer garantias fundamentais e sociais. Na qual se incluí o direito à educação, com previsão no artigo $6^{\circ}$ da Carta Magna, senão vejamos:

Art. $6^{\circ}$ São direitos sociais a educação, a saúde, a alimentação, o trabalho, a moradia, o lazer, a segurança, a previdência social, a proteção à maternidade e à infância, a assistência aos desamparados, na forma desta Constituição.

Além deste dispositivo, o direito á educação possuí um capítulo especifico na Constituição (Seção I, Capitulo III do Titulo VIII), disciplinado pelos artigos 205 a 214, onde estabelece, de inicio, que a educação é um direito de todos, dever do estado e da família, que com a colaboração da sociedade, tem por objetivo proporcionar o pleno desenvolvimento da pessoa, preparando-a para o exercicio da cidadania e sua qualificação para o trabalho. (g.n.)

Cabe ressaltar, que por meio de sumula vinculante de número 12, o STF proferiu entendimento de que a cobrança de taxa de matricula nas Universidades públicas afronta o inciso IV do artigo 206, isto porque, tal dispositivo elenca uma série de princípios que visam reger o ensino no Brasil, são eles a garantia de I - igualdade de condições para o acesso e permanência na escola; II - liberdade de aprender, ensinar, pesquisar e divulgar o pensamento, a arte e o saber; III - pluralismo de idéias e de concepções pedagógicas, e coexistência de instituições públicas e privadas de ensino; IV - gratuidade do ensino público em estabelecimentos ofi-

\section{Paulo, Vicente e Alexandrino, Marcelo. Direito Constitucional Descomplicado. Gen. 2011 pg 1.}

74 - Revista do Curso de Direito da Faculdade de Humanidades e Direito, v. 14, n. 14, Edição Especial 2017 
ciais; V - valorização dos profissionais da educação escolar, garantidos, na forma da lei, planos de carreira, com ingresso exclusivamente por concurso público de provas e títulos, aos das redes públicas; VI - gestão democrática do ensino público, na forma da lei; VII - garantia de padrão de qualidade; VIII - piso salarial profissional nacional para os profissionais da educação escolar pública, nos termos de lei federal.

Conforme já explanado, é dever do Estado, em conjunto com a família e a sociedade, garantir o direito à educação. No que se refere a esta garantia de dever do Estado, o artigo 208 estabelece que:

Art. 208. O dever do Estado com a educação será efetivado mediante a garantia de:

I - educação básica obrigatória e gratuita dos 4 (quatro) aos 17 (dezessete) anos de idade, assegurada inclusive sua oferta gratuita para todos os que a ela não tiveram acesso na idade própria;

II - progressiva universalização do ensino médio gratuito;

III - atendimento educacional especializado aos portadores de deficiência, preferencialmente na rede regular de ensino; IV - educação infantil, em creche e pré-escola, às crianças até 5 (cinco) anos de idade; V - acesso aos níveis mais elevados do ensino, da pesquisa e da criação artística, segundo a capacidade de cada um;

VI - oferta de ensino noturno regular, adequado às condições do educando;

VII - atendimento ao educando, em todas as etapas da educação básica, por meio de programas suplementares de material didáticoescolar, transporte, alimentação e assistência à saúde. $\S 1^{\circ} \mathrm{O}$ acesso ao ensino obrigatório e gratuito é direito público subjetivo.

$\S 2^{\circ} \mathrm{O}$ não-oferecimento do ensino obrigatório pelo Poder Público, ou sua oferta irregular, importa responsabilidade da autoridade competente.

$\S 3^{\circ}$ Compete ao Poder Público recensear os educandos no ensino fundamental, fazer-lhes a chamada e zelar, junto aos pais ou responsáveis, pela freqüência à escola. 
Essas obrigações criam um direito público subjetivo e, portanto, no caso da omissão do Estado ou a violação de um desses dispositivos constitucionais, a autoridade competente é responsabilizada, cabendo uma possível ação civil.

Além disso, no tocante à educação, cabe ao Estado interferir na iniciativa privada, no que diz respeito à autorização e avaliação de qualidade, utilizando-se de seu poder de policia administrativa, para fiscalizar o cumprimento das normas gerais da educação nacional, que dentre uma série de parâmetros, fixa conteúdo mínimo para o ensino fundamental, garantindo, desta forma, a formação básica comum, facultando o ensino religioso e vedando-o como disciplina obrigatória.

O ensino fundamental regular deverá ser ministrado em lingua portuguesa, sendo assegurado às comunidades indígenas também a utilização de suas línguas maternas e processos próprios de aprendizagem.

Ainda sobre as normas gerais da educação nacional, o ensino fundamental deve ser ministrado em vernáculo, ou seja, em português, a língua oficial do Brasil, permitindo aos indígenas.

Quanto ao investimento Estatal à educação, o artigo 212 estabelece que a União aplicará, anualmente, nunca menos que dezoito por cento, e os estados, o Distrito Federal e os municipios nunca menos que vinte e cinco por cento, da receita resultante de impostos compreendida a proveniente de transferências, na manutenção e desenvolvimento do ensino, não sendo considerando os impostos de transferida pela União aos estados, ao Distrito Federal e aos municipios, ou pelos estados aos respectivos municipios.

Os recursos publicos serão destinados às escolas públicas, sendo permitido que sejam destinadas ás escolas comunitárias, confessionais ou filantrópicas, desde que estas comprovem finalidade não lucrativa e apliquem seus excedentes financeiros em educação e, assegurem a destinação de seu patrimônio a outra escola comunitária, filantrópica ou 
confessional, ou ao Poder Público, no caso de encerramente de suas atividades.

Estes recursos podem ser destinados a bolsas de estudo, para os que demonstrarem insuficiencia de recursos, quando houver falta de vagas e cursos regulares da rede pública na localidade da residência do educando, ficando o Poder Público obrigado a investir prioritariamente na expansão de sua rede na localidade.

As atividades universitárias de pesquisa e extensão poderão receber apoio financeito do Poder Público, como é o caso das bolsas PIBIC (Projeto de iniciação cientifica) do CNPQ (Conselho Nacional de Pesquisa), ou as bolsas de pesquisa da FAPESP (Fundação de Amparo à pesquisa do Estado de São Paulo) ou mesmo as bolsas de intercambio do programa "Ciência sem Fronteira".

A lei estabelecerá o Plano Nacional de Educação (PNE), de duração plurianual, visando à articulação e ao desenvolvimento do ensino em seus diversos niveis e à integração das ações do Poder Público para que tenha por resultados básicos a erradicação do analfabetismo; a universalização do atendimento escolar; melhoria da qualidade do ensino; formação para o trabalho; promoção humanística, científica e tecnológica do País e o estabelecimento de meta de aplicação de recursos públicos em educação como proporção do produto interno bruto.

A Emenda Constitucional $n^{\circ} 59 / 2009$ (EC n 59/2009) mudou a condição do Plano Nacional de Educação (PNE), transformando-o de uma disposição transitória da Lei de Diretrizes e Bases da Educação Nacional (Lei nº 9.394/1996) em uma exigência constitucional com periodicidade decenal. Com isso, o PNE é utilizado como base para a elaboração dos planos estaduais, distrital e municipais, que, ao serem aprovados em lei, devem prever recursos orçamentários para a sua execução. 
Em 2014 foi aprovado o novo Plano Nacional de Educação, por meio da lei $\mathrm{N}^{\circ} 13.005 / 2014^{3}$ que estabelece vinte metas $^{4}$ a serem cumpridas de 2014 a 2024, entre elas está a erradicação do analfabetismo; o aumento de vagas em creches, no ensino médio, no profissionalizante e nas universidades públicas; a universalização do atendimento escolar para crianças de 4 a 5 anos e a oferta de ensino em tempo integral para, pelo menos, 25\% dos alunos da educação básica; elevar a taxa de alfabetização da população com quinze anos ou mais para noventa e três vírgula cinco por cento, erradicar o analfabetismo absoluto e reduzir em cinquenta por cento a taxa de analfabetismo funcional. Para isso o investimento em educação irá aumentar gradativamente, dos atuais 5,3\%, até atingir o equivalente a $10 \%$ do PIB ao ano.

Não podemos deixar de citar que o ECA (Estatuto da Criança e do Adolescente), prevê expressamente em seu artigo 53 o direito á Educação às crianças e aos adolescentes. Assegurando-lhes: I - igualdade de condições para o acesso e permanência na escola; II - direito de ser respeitado por seus educadores; III - direito de contestar critérios avaliativos, podendo recorrer às instâncias escolares superiores; IV - direito de organização e participação em entidades estudantis; V acesso à escola pública e gratuita próxima de sua residência.

No que se refere ao Direito Internacional, a Declaração Americana dos Direitos e Deveres do Homem, aprovada em Bogotá, em abril de 1948, em seu artigo XII, estabelece que

Toda pessoa tem direito à Educação, que deve inspirar-se nos princípios de liberdade, moralidade e solidariedade humana. Tem outrossim, direito a que, por meio dessa educação, lhe

3 Brasil, Plano Nacional de Educação - lei no 13.005/2014. Disponível na internet, por meio do site < http://www.planalto.gov.br/CCIVIL_03/_ Ato2011-2014/2014/Lei/L13005.htm> Acesso em 05/06/2017.

4 Conheça as vinte metas do Plano Nacional de Educação, atráves do endereço < http://pne.mec.gov.br/images/pdf/pne_conhecendo_20_metas. pdf $>$ Acesso em 05/06/2017.

78 - Revista do Curso de Direito da Faculdade de Humanidades e Direito,

v. 14, n. 14, Edição Especial 2017 
seja proporcionado o preparo para subsistir de uma maneira digna, para melhorar o seu nível de vida e para poder ser útil à sociedade. $\mathrm{O}$ direito à educação compreende o de igualdade de oportunidade em todos os casos, de acordo com os dons naturais, os méritos e o desejo de aproveitar os recursos que possam proporcionar a coletividade e o Estado. Toda pessoa tem o direito de que lhe seja ministratada gratuitamente pelo menos, a instrução primária.

Também nesse sentido, a Declaração Internacional dos Direitos Humanos em seu artigo XXVI, dispõe que "Toda a pessoa tem direito à instrução. A instrução deve ser gratuita, pelo menos a correspondente ao ensino elementar fundamental. O ensino elementar é obrigatório. O ensino técnico e profissional dever ser generalizado; o acesso aos estudos superiores deve estar aberto a todos em plena igualdade, em função do seu mérito. 2.A educação deve visar à plena expansão da personalidade humana e ao reforço dos direitos do Homem e das liberdades fundamentais e deve favorecer a compreensão, a tolerância e a amizade entre todas as nações e todos os grupos raciais ou religiosos, bem como o desenvolvimento das actividades das Nações Unidas para a manutenção da paz. 3.Aos pais pertence a prioridade do direito de escholher o género de educação a dar aos filhos."

Ainda sobre o Direito Internacional, o Pacto Internacional sobre direitos economicos, sociais e culturas, promulgado por Decreto n. 591/92 em seu artigo 13, a Declaração sobre o Direito ao Desenvolvimento, em seu artigo $8^{\circ}$ e a Convenção Sobre os Direitos da Criança, em seu artigo 18, estabelece garantias de acesso à educação.

Com isso, podemos concluir, que não só é o objetivo do Brasil, mas também do mundo, assegurar o direito à educação, isto porque, resta claro que a educação é responsavél pela formação do indivíduo virtuoso na sociedade. 


\section{ENSINO VERSUS EDUCAÇÃO}

A etimologia da palavra "educar" vem do latim "educare" ou "educere" que significa "conduzir para fora" ou "direcionar para fora”. Nesta concepção, busca-se conduzir o indivíduo para fora da ignorância de si mesmo, ou seja, mostrar a ele um mundo diversificado de opiniões, onde não prevalece apenas um pensamento. A falta deste, o torna alguém limitado mediante ao seu mínimo entendimento não tendo a capacidade de ter uma visão ampliada do mundo em que ocorre a transição da vida. Tendo em vista que educar é a passagem do mundo da ignorância para o mundo do conhecimento, essa transação ocorre pelo o instrumento da "Educação", em uma definição ampla a palavra quer dizer o ato de educar, ou seja, de fato é conduzir o indivíduo para fora da ignorância que se vive. Somente é possivel educar por meio da educação.

E o que seria, pois o ensino? Está relacionado com os termos educar e educação, pois é o método de aplicação do conhecimento por diversos meios e técnicas. O ensino é formado por três pilares, para sua concretização. Aquele que possui a fonte de conhecimento na figura do professor, o aluno aquele que recebe e o objeto do conhecimento, ou seja, a mensagem que será transmitida.

Como se pode observar, não existe a possibilidade de se ter o significado das palavras individualmente, sendo que elas se completam.

A Constituição Federal como a carta magna em nosso ordenamento jurídico brasileiro, trás como direito social a "educação" sendo prevista em seu no art. $6^{\circ}$, amparado pelos artigos 205 e seguintes, onde aborda o tema atribuindo como dever do Estado garantir a todos em parceria com as famílias com o objetivo do desenvolvimento da pessoa, seu preparo para o exercício da cidadania e sua qualificação do trabalho. Além disso, deverá sem seguidos os princípios que regem a educação pela Constituição Federal conforme preceitua o art. 206. 
A sociedade é formada por pilares de sustentação, essas pilares devem estar erguidos em bases firmes e concretas para que a sociedade possa se desenvolver, sendo a educação a base fundamental que dá a solidez necessária para que isso ocorra. Não é necessária uma análise técnica para se ver que enfrentamos uma crise social, onde se deixa de lado aquilo que leva ao crescimento e desenvolvimento de uma nação.

Do ponto de vista histórico, somente no século XX ocorreu à amplificação da escolarização básica no Brasil, no que se refere à rede pública de ensino no final da década de 1970, início década de 1980.

Ocorre que há um descompasso, o qual nos leva a uma dúvida que não deveria existir. Se, mediante a análise história houve a evolução da sociedade, por que a educação ainda é um tema que nos trás insegurança?

Para Weber ${ }^{5}$, a sociedade é o conjunto de ações individuais que se orientam pelas ações dos outros e a partir do momento que se estabelece uma comunicação entre os indivíduos, estamos diante da ação social. Partindo desse conceito, a sociedade evoluída é aquela onde o ser humano possui a liberdade de expressar suas ideias e pensamentos, agir nos parâmetros da lei, ir e vir sem se preocupar com que o próximo irá pensar sobre as ações que executam. Com essas palavras, estamos diante do processo da educação, conforme já mencionado é a passa da ignorância para a sensibilidade de entender que existem diversas opiniões e não somente a dele.

Como já mencionado, a educação é a parceria da família com o Estado. Essa deve executar seu papel expondo desde cedo os princípios e valores sócios culturais inseridos na sociedade em que se vive, entendendo que cobrar do Estado uma educação de qualidade faz parte de sua formação, ou seja, a família educa baseado nos princípios de formação no crescimento do indivíduo inserido na sociedade, já o Estado

5 Max Weber apud Maria Clara Nery. Sociologia Contemporânea. IESDE. 2007, p. 38 . 
o educa afim de profissionalizá-lo para o mercado de trabalho como cidadão conhecedor de seus direitos. Sendo uma parceria, não se encontra um bom resultado se somente uma das partes cumprirem seu papel.

Quando se entende que o ensino é a consequência na linha de sucessão de educação de qualidade, fica claro que temos um progresso em nossa sociedade. Os métodos e as técnicas de aprendizagem são escolhidos de acordo com as necessidades e idades de cada indivíduo, amparado por recursos disponibilizados pelo Governo, responsável como visto por uma educação de qualidade. Aquele que se sentir lesado deverá nos termos da lei reivindicar seus direitos uma vez que estiver cumprindo com a sua parte.

$\mathrm{Na}$ atual sociedade em que vivemos o quadro de ensino e educação infelizmente tem sido crítico. Não há uma estrutura adequada para que se tenha avanço educacional, sendo que a cada dia a qualificação dessa estrutura vem sendo desvalorizada. O governo parece não estar preocupado com esse desenvolvimento, pois é muito mais fácil deixar as pessoas na esfera da ignorância, do que prepará-los afim de que possam sair da esfera do senso comum, tendo opinião própria para reivindicar seus direitos, dessa forma manipular a população é a saída para que se consiga uma política corrupta cujo objetivo é a valorização do senso comum.

Existem os meios criados pelo próprio Governo para que todos tenham acesso a educação, porém se tornam inviáveis por tamanha burocracia criada para que se consiga. Em um mundo capitalista, as pessoas preferem se submeterem a trabalhos que podem ser considerados "escravos" mas que garantem o sustento da família, a ter que passar horas em filas e submeter-se a situações muitas vezes constrangedoras para conseguir acesso à educação.

A ignorância leva o indivíduo à zona de conforto, uma vez que não se vai atrás dos próprios direitos.

Até que ponto os subsídios "dados" pelo governo podem ser considerados válidos uma vez que limitam a atuação dos profissionais dessa área? O grande problema é política corrupta que não permite o pleno desenvolvimento desses profissionais, 
que muitas vezes não são nem preparados para desempenharem tal função, sendo desvalorizados com falta de recursos e até mesmo um salário digno. Espera-se que o professor faça milagres dentro da sala de aula e infelizmente essa é a visão da sociedade e também do governo. O desempenho de todos, faria com que a atual situação da educação e ensino, tivesse seu quadro revertido em resultados satisfatórios.

Diante do exposto, vimos que os termos "ensino" e "educação" se complementam não podendo ser analisados isoladamente. O ensino é a maneira a qual será repassado o conhecimento, ou seja, o método de aplicação para que o seja instituído perante a sociedade. Já a educação é o instrumento que tira o ser humano do mundo da ignorância, mostrando não haver somente uma opinião válida, mas que todas devem ser respeitadas de forma única.

\section{ENSINO PÚBLICO NO BRASIL (ASPECTOS HISTÓRI- COS E SOCIAIS)}

\subsection{O ENSINO FUNDAMENTAL E MÉDIO PÚBLICO}

Ao realizar pesquisas acerca da qualidade (ou da falta desta) no ensino público em nosso país, as informações encontradas são alarmantes, tanto no que concerne ao ensino básico e fundamental, quanto ao ensino médio. A discrepância existente entre os índices de aproveitamento das instituições da rede privada em face da rede pública beiram a irrealidade. Isso, sem mencionar que as instituições públicas, nas avaliações de aproveitamento, têm obtido resultados cada vez mais preocupantes, do ponto de vista social.

Em artigo publicado no site da revista Época, Camila Guimaraes $^{6}$, aduz que de acordo com a avaliação da Prova Brasil, o ensino público brasileiro é "ruim, desigual e estagnado":

6 GUIMARAES, Camila. O ensino público no Brasil: ruim, desigual e estagnado. Disponivel na internet, por meio do site:http://epoca.globo. com/ideias/noticia/2015/01/bo-ensino-publico-no-brasilb-ruim-desigual-e-estagnado.html. Publicado em 05/01/2015. 
Mais de $65 \%$ dos alunos brasileiros no $5^{\circ}$ ano da escola pública não sabem reconhecer um quadrado, um triângulo ou um círculo. Cerca de 60\% não conseguem localizar informações explícitas numa história de conto de fadas ou em reportagens. Entre os maiores, no $9^{\circ}$ ano, cerca de $90 \%$ não aprenderam a converter uma medida dada em metros para centímetros, e $88 \%$ não conseguem apontar a ideia principal de uma crônica ou de um poema. Essas são algumas das habilidades mínimas esperadas nessas etapas da escola, que nossos estudantes não exibem. É o que mostram os resultados da última Prova Brasil, divulgados pelo governo federal no final de novembro. A prova avalia, a cada dois anos, o desempenho de alunos do $5^{\circ}$ e do $9^{\circ}$ ano em português e matemática. É usado para compor o principal indicador de qualidade da educação do país, o Índice de Desenvolvimento da Educação Básica (IDEB). Os resultados revelam, no entanto, algo ainda mais perigoso que o baixo desempenho: a desigualdade. Enquanto em alguns Estados do Sul, como São Paulo e Santa Catarina, metade dos alunos tem aprendizado adequado em português, Estados como Alagoas e Maranhão não chegam a ter $20 \%$. [...] "Se a educação é um direito de todos, o direito de cada aluno que não aprende - considerado adequado vem sendo negado", diz Ernesto Martins Faria, coordenador de projetos da Fundação Lemann, organização sem fins lucrativos que atua para melhorar a qualidade da educação. (g.n.)

O cenário atual da educação pública no país, realmente encontra-se estagnado, tendo em vista que "a sociedade não está interessada no debate sobre educação"7. O que se observa é que não há, por parte da massa popular, verdadeiro pleito por melhorias no setor educacional; há na verdade, um conformismo coletivo a respeito dos serviços educacionais prestados pelo Estado Brasileiro. Segundo João Batista Oliveira, embora o país tenha avançado no que diz respeito

7 GUIMARAES, Camila apud OLIVEIRA, João Batista. A sociedade não está interessada no debate sobre educação. Disponível na internet, por meio do site: http://epoca.globo.com/vida/noticia/2014/11/joao-batista-oliveira-sociedade-nao-esta-binteressadab-no-debate-sobre-educacao.html.

Publicado em 11/11/2014.

84 - Revista do Curso de Direito da Faculdade de Humanidades e Direito, v. 14, n. 14, Edição Especial 2017 
ao número de crianças matriculadas nas escolas, o ensino propriamente dito não avançou, não houve investimento em tal setor com fins de aumento da qualidade.

O questionamento inevitável, a esta altura da explanação, é se o Estado Brasileiro, por meio de seus mecanismos governamentais, tem de fato cumprido com os deveres a ele inerentes no campo educacional por intermédio dos mandamentos constitucionais.

\subsection{O ENSINO SUPERIOR PÚBLICO}

No decorrer das últimas décadas o ensino superior alcançou posição de prestígio dentre os objetivos dos brasileiros; por intermédio dela são formados, especializados e qualificados centenas de profissionais que visam melhor colocação ante o concorrido mercado de trabalho.

Segundo o Portal Brasil ${ }^{8}$, há três modalidades que o brasileiro pode optar para cursar o ensino superior, quais sejam: bacharelado, licenciatura e formação tecnológica. O ensino superior no Brasil é oferecido por universidades, centros universitários, faculdades, institutos superiores e centros de educação tecnológica. Ressaltando que os cursos de pós-graduação são divididos entre lato sensu (especializações e $M B A s$ ) e strictu sensu (mestrados e doutorados).

Existem os cursos presenciais, em que o graduando necessita ter $75 \%$ de frequências nas aulas; há os cursos à distância, denominados ensino à distância (EAD), nesta modalidade o aluno conta com a ajuda da internet; por fim, existem cursos semipresenciais, com aulas em sala de aula e em ambiente virtual.

A qualidade do ensino superior é avaliada pelo INEP (Instituto Nacional de Estudos e Pesquisas Educacionais Anísio Teixeira) e o MEC (Ministério da Educação e Cultura) que se

8 Saiba como funciona o ensino superior no Brasil. Disponivel na internet via <http://www.brasil.gov.br/educacao/2009/11/ensino-superior> Acesso em 05/06/2017. 
utilizam do IGC (Índice Geral de Cursos), que é divulgado uma vez ao ano, após a publicação dos resultados do ENADE (Exame Nacional de Desempenho de Estudantes).

Para o acesso à graduação, o interessado possui as seguintes opções: prestar vestibular, que é a forma mais tradicional de avaliar o candidato, testando seus conhecimentos nas disciplinas cursadas no ensino médio; prestando a prova do ENEM (Exame Nacional do Ensino Médio), que trás questões objetivas acerca do conteúdo ministrado também no ensino médio; realizando a Avaliação Seriada no Ensino Médio, que acontece de forma gradual e progressiva, com provas aplicadas ao final de cada semestre do ensino médio; há universidades que se baseiam também, para a seleção, em entrevistas ou nas informações pessoais e profissionais dos candidatos (como grau de escolaridade, cursos, histórico escolar, etc.).

O Estado brasileiro também conta com programas e projetos que tem o escopo de facilitar o ingresso do estudante e de docentes na graduação: FIES (Fundo de Financiamento ao Estudante do Ensino Superior), que nada mais é, do que um financiamento para aqueles que não possuem condições de arcar com os custos da graduação; PIBID (Programa Institucional de Bolsas de Iniciação à Docência), que consiste em bolsas de iniciação à docência para alunos de cursos presenciais que se dedicam ao estágio em escolas públicas e que graduados se comprometeram a trabalhar no magistério da rede pública de ensino; PIBIC (Programa Insticucional de Bolsas de Iniciação Cientifica); PROUNI (Programa Universidade para Todos), criado em 2004 pela Lei 11.096/2005, concede bolsas de estudos integrais e parciais a estudantes de cursos de graduação e de cursos sequenciais de formação específica, sempre em instituições privadas de educação superior; REUNI (Programa de Apoio a Planos de Reestruturação e Expansão das Universidades Federais), consista na busca da ampliação do acesso e a permanência na educação superior; 
e por fim, o PROMISAES (Projeto Milton Santos de Acesso ao Ensino Superior), que consiste no fomento a cooperação técnico-científica e cultural entre o Brasil e os países - em especial os africanos - nas áreas de educação e cultura.

Eunice R. Durham ${ }^{9}$, em profunda análise sobre o tema, em seus caracteres históricos aponta que:

Duas características importantes marcam o desenvolvimento do ensino superior no Brasil. O primeiro é seu caráter tardio, pois as primeiras instituições de ensino superior são criadas apenas em 1808 e as primeiras universidades são ainda mais recentes, datando da década de 30 do século XX. O segundo [...], é o desenvolvimento precoce de um poderoso sistema de ensino privado paralelo ao setor público. Já na década de 1960 , este setor adquire novas características. Não se trata mais, de fato, da coexistência de sistemas públicos e privados com missões e objetivos semelhantes como antes. Trata-se de outro sistema que subverte a concepção dominante de ensino superior centrada na associação entre ensino e pesquisa, na liberdade acadêmica e no interesse público.

Logo, o que observamos é que para melhor entendimento da situação contemporânea do ensino superior no Brasil, é necessária uma breve análise de seu histórico. Segundo Durham, em tal história notam-se períodos que acompanharam as transformações políticas que ocorriam no país:

O primeiro, que coincide com o período monárquico, vai de 1808 até o início da República, em 1889. É caracterizado pela implantação de um modelo de escolas autônomas para formação de profissionais liberais, de exclusiva iniciativa da Coroa. No segundo periodo, que abrange toda a Primeira República, de 1889 a 1930, o sistema se descentraliza e, ao lado das escolas federais, surgem outras, tanto públicas (estaduais ou municipais), quanto privadas. Até o final deste período, não há

9 Eunice R. Durham. O ensino superior no Brasil: público e privado. Disponibilizado na internet via < http://nupps.usp.br/downloads/docs/ dt0303.pdf $>$. Acesso em 21/01/2016. 
universidades no Brasil, apenas escolas superiores autônomas centradas sem um curso. O período subsequente é gestado na década de 20 do século passado, mas se implanta em 1930 e coincide com o final da Primeira República e a instalação do governo autoritário de Getúlio Vargas, o Estado Novo. É nesta época que são criadas as primeiras universidades do país. Este período se encerra em 1945, com a queda de Vargas e a redemocratização do país, iniciando um novo período que se estende até 1964 e é caracterizado pela ampliação do número de universidades públicas. O período seguinte se inicia em 1964, quando se instala um novo período autoritário, durante o qual o modelo de universidade é reformado e o sistema privado se desenvolve aceleradamente no sentido da constituição do que Geiger denomina "massprivate sector" (Geiger, 1986). O período recente se inicia com o processo de redemocratização gradual do país, em 1985 e é marcado pela Constituição de 1988, por uma nova Lei de Diretrizes e Bases da Educação Nacional (LDB) de 1996 e por profundas transformações politicas econômicas e educacionais. Distinguimos, neste período, aquele que vai de 1995 a 2002, que coincide com os dois mandatos do Presidente Fernando Henrique Cardoso. Este período acabou de se encerrar neste ano de 2003 e há uma profunda incerteza sobre os rumos que tomará o ensino superior daqui para frente.

O convivio entre as instituições de ensino superior público e privado tem gerado grande debate entre os profissionais do meio. João Carlos Cardoso ${ }^{10}$, em seu blog virtual do jornal GGN, aponta os prós e contras de cada uma das modalidades, concluindo que:

Temos, há muito tempo, um grave problema: não sabemos como estruturar o nosso sistema de educação superior. A partir dos anos noventa acreditou-se que a estratégia da abertura para o mercado e a criação de um modelo dual público/privado poderiam fazer avançar quanti e qualitativamente o Ensino superior.

${ }^{10}$ CARDOSO, João Carlos. Comparações entre o ensino superior público e o privado. Disponivel na internet via < http://jornalggn.com.br/blog/ luisnassif/comparacoes-entre-o-ensino-superior-publico-e-o-privado> Acesso em $21 / 01 / 2016$.

88 - Revista do Curso de Direito da Faculdade de Humanidades e Direito, v. 14, n. 14, Edição Especial 2017 
Fez avançar, sim, mas apenas do ponto de vista quantitativo. Não resolveu a questão de gestão do ensino público, pois este é fechado às mudanças, e enfrenta problemas na qualidade da graduação tanto pública quanto privada. O mercado está sendo inundado por profissionais formados nos dois modelos e não se sabe aonde isso vai nos levar. A mais atraso, provavelmente.

\section{ACESSO ÀS UNIVERSIDADES PRIVADAS}

\subsection{EXPANSÃO DA PRIVATIZAÇÃO DO ENSINO SUPERIOR}

Foi com a reforma econômica, ocorrida durante os governos de Fernando Henrique Cardoso e Luiz Inácio Lula da Silva, que ocorreram mudanças significativas em relação à política educacional brasileira, em especial na educação superior.

O neoliberalismo trouxe a privatização desse nivel de ensino, com a expansão do setor privado, assim como a privatização das Instituições de Ensino Superior públicas. Esse movimento transformou a universidade pública em um modelo educacional que privilegia a mercantilização do ensino como a principal forma de superação da crise institucional que ela vivencia; ou seja, são criadas fundações de direito privado; cobranças de taxas de mensalidades de cursos de pós-graduação lato sensu; convênios e contratos de prestação de serviço com empresas privadas para o desenvolvimento das atividades de ensino, pesquisa e extensão, com a finalidade de captar recursos no mercado.

O Brasil adotou na reforma da educação superior, a redução dos investimentos públicos, bem como diversificou as fontes de financiamento, por orientação do Banco Mundial, que acreditava que a crise da educação brasileira tinha como origem o modelo de universidade de pesquisa, ou seja, um modelo unificado e oneroso:

[...] maior autonomia institucional é a chave para o êxito da reforma do ensino público superior, especialmente a fim de diversificar e utilizar os recursos mais eficientemente (...). A experiência demonstra que se quer em que as instituições estatais 
melhorem sua qualidade e eficiência, os governos deverão efetuar reformas importantes no financiamento a fim de mobilizar mais recursos privados para o ensino superior em instituições estatais (...) de várias maneiras: mediante a participação dos estudantes nos gastos; arrecadação de recursos de ex-alunos; utilização de fontes externas; realização de outras atividades que gerem receitas (Banco Mundial, 1995, p. 44 e 69)

Para Vera Lúcia Jacob Chaves, Rosângela Novaes Lima e Luciene Miranda Medeiros, no tema Reforma da educação superior brasileira - de Fernando Henrique Cardoso a Luiz Inácio Lula da Silva: politicas de expansão, diversificação e privatização da educação superior brasileira, após dez anos da promulgação da LDB - Lei de Diretrizes e Bases da Educação Nacional (Lei 9.394/96), dados evidenciados no estudo que fizeram revelam que a política expansionista adotada pelos governos de Fernando Henrique Cardoso e Luiz Inácio Lula da Silva, por meio da diversificação institucional e pelo aprofundamento da privatização do ensino superior, sem acréscimo de recursos públicos, apesar de ter promovido a expansão do acesso, não corresponde à grande demanda populacional existente, em especial, na faixa etária de 18 a 24 anos.

O Censo da Educação Superior demonstra que apenas $10,5 \%$ desses jovens tiveram acesso à educação superior sendo que a maioria expressiva dos alunos matriculados no ensino superior brasileiro, $73,2 \%$, está no setor privado e em instituições isoladas de ensino que não desenvolvem pesquisa e extensão. ${ }^{11}$

A política pública de expansão da educação de nível superior apresentou alguns instrumentos inclusivos aos estudantes universitários: o Fundo de Financiamento Estudantil (instituído pela Lei $\mathrm{n}^{\circ}$ 10.260, de 12 de julho de 2001) e as bolsas

\footnotetext{
11 Educação superior no Brasil - 10 anos pós-LDB / Mariluce Bittar, João Ferreira de Oliveira, Marília Morosini (Organizadores). - Brasília: Instituto Nacional de Estudos e Pesquisas Educacionais Anísio Teixeira, 2008. (p. 343-346)
}

90 - Revista do Curso de Direito da Faculdade de Humanidades e Direito, v. 14, n. 14, Edição Especial 2017 
do Programa Universidade para Todos. Ambos os programas fazem parte do Plano Nacional da Educação - PNE, criado a partir da discussão nas Conferências de Educação, no âmbito municipal, estadual e nacional, levado a termo no Congresso Nacional. Com isso, ratificou-se o compromisso de um Estado de Direito, que busca a equidade e a justiça social.

\subsection{FIES - FUNDO DE FINANCIAMENTO ESTUDANTIL}

Para tanto, esse Fundo, sucessor do Crédito Educativo, firmou-se como saída para o crescimento inclusivo, criando oportunidade de ingresso ao ensino superior privado (com avaliação positiva nos processos conduzidos pelo Ministério da Educação - MEC, de acordo com regulamentação própria do Sistema Nacional de Avaliação da Educação Superior) e, consequentemente, contribuindo para o desenvolvimento econômico do país.

Em 2010, o FNDE assumiu a operacionalização do Fies, que passou a contar: com a criação do Fundo de Garantia de Operações de Crédito Educativo (FGEDUC), que dispensa a apresentação de fiador e possibilita o pagamento desse financiamento com trabalho; taxa de juros de 3,4\% ao ano; o limite máximo de financiamento foi elevado para até $100 \%$ do valor do curso; a carência foi ampliada para 18 meses após a formatura; o prazo de quitação passou a ser de até 03 vezes o período financiado do curso. Resultado: 1 milhão de contratos de financiamento estudantil, em agosto de 2013, sendo 96\% estudantes das classes C, D e E com renda familiar mensal bruta de até 10 salários mínimos.

Segundo o Relatório de Gestão do Exercício de 2014, do Ministério da Educação - Secretaria de Educação Superior ${ }^{12}$, essa modalidade de financiamento estudantil oportunizou o ingresso de estudantes em cursos com mensalidades mais

12 Ministério da Educação - Secretaria de Educação Superior, FIES - Prestação de Contas Ordinárias Anual, Relatório de Gestão do Exercício de 2014 - Abril de 2015 (p. 4). 
elevadas, como é o caso de medicina e engenharia. Até 2013, a demanda por financiamento com recursos do Fies tem crescido em média 100\% ao ano, mas já em 2014 o crescimento foi de apenas $31 \%$.

\subsection{ACESSO ÀS INFORMAÇÕES E À INSCRIÇÃO}

A seguir, segue o conteúdo extraído do portal do MEC, cujo acesso do estudante ao Fundo de Financiamento Estudantil - Fies se dá por meio do sítio do Ministério da Educação ${ }^{13}$, o qual disponibiliza várias informações sobre o Programa e a orientação para inscrição (isenta de taxas) feita exclusivamente pela internet.

Para inscrever-se é necessário que o estudante: não tenha concluído nivel superior; tenha renda familiar bruta, por pessoa, de dois e meio salários mínimos; e tenha participado de alguma das edições do Exame Nacional do Ensino Médio (Enem) a partir de 2010 e obtido nota mínima de 450 pontos na média das provas e nota da redação superior à zero. Podem se inscrever ainda, independentemente de participado do Enem: os estudantes que tenham concluído o ensino médio antes de 2010; os professores do quadro permanente da rede pública de ensino, em efetivo exercício na educação básica, desde que se inscrevam em cursos de licenciatura, normal superior ou pedagogia na sua área de atuação. Nesse caso, podem participar também os professores que tenham concluído curso superior.

As inscrições podem ser feitas duas vezes ao ano. A partir do segundo dia de inscrição, são divulgadas notas de corte parciais de cada curso. O estudante pode acompanhar as notas de corte e alterar a sua opção de curso até o encerramento das inscrições; ela é apenas uma referência para ajudar o candidato no monitoramento de sua inscrição.

Após a divulgação do resultado do processo seletivo, a classificação se dará de acordo com a nota obtida no Enem;

13 Em http://fiesselecao.mec.gov.br.

92 - Revista do Curso de Direito da Faculdade de Humanidades e Direito,

v. 14, n. 14, Edição Especial 2017 
ou no caso de não ter participado do exame, de acordo com o indice calculado a partir das informações socioeconômicas prestadas na inscrição.

Ainda segundo o portal do MEC, os estudantes classificados com base no número de vagas do curso serão pré-selecionados na chamada única e devem concluir a inscrição no Sistema Informatizado do Fies (SisFies) ${ }^{14}$, no período programado.

\subsection{CONTRATAÇÃO DO FINANCIAMENTO}

Após a conclusão da inscrição no SisFies, o estudante deve: validar as informações na Comissão Permanente de Supervisão e Acompanhamento da instituição de ensino em até 10 dias, contados a partir do dia seguinte ao da conclusão da inscrição. Comparecer a um agente financeiro do Fies em até 10 dias contados a partir do terceiro dia útil seguinte à data da validação das informações pela referida Comissão.

Os financiamentos concedidos com recursos do Fies ${ }^{15}$ a partir do segundo semestre de 2015 têm taxa de juros de $6,5 \%$ ao ano.

\subsection{COMPETENCIAS DOS AGENTES}

A gestão do Fies compete ao MEC, que gerencia a política de oferta de financiamento e supervisiona todo o processo que envolve: o Fundo, o agente operador, o agente financeiro, as instituições de ensino superior particulares e os estudantes. Já o Fundo Nacional de Desenvolvimento da Educação (FNDE) é o agente que opera e administra os ativos e passivos. A Caixa Econômica Federal e o Banco do Brasil passaram a atuar como agentes financeiros do Fies, efetuando as contratações com os estudantes, bem como a cobrança e a execução dos contratos inadimplentes.

\footnotetext{
${ }^{14}$ Diponivel na internet via <http://sisfiesportal.mec.gov.br> Acesso em 05/06/2017.

${ }^{15}$ Disponível na internet via <http://fiesselecao.mec.gov.br/index. php?pagina=faq\#conhecendo $>$ Acesso em 05/06/2017.
} 


\subsection{PROUNI - PROGRAMA UNIVERSIDADE PARA TODOS}

Esse programa foi instituído pelo governo federal, por meio da Lei $n^{\circ} 11.096$, de 13 de janeiro de 2005, como uma forma de remediar o número insuficiente de vagas nas universidades públicas. Além do que, as vagas acabavam sendo preenchidas, na maioria das vezes, por aqueles que tinham melhor base escolar, os oriundos das escolas particulares, salvo os casos excepcionais.

É irônico, pois justamente quem não tinha condições de pagar por um curso superior particular, acabava ficando de fora da universidade pública devido à baixa pontuação obtida no resultado da Fuvest (vestibular especifica da Universidade de São Paulo - USP). Note-se que após os exames realizados em duas fases, o estudante permanecia no curso escolhido durante todo o período necessário para a sua formação. Ou seja, o preparo conseguido por meio do ensino particular de qualidade dava ao estudante uma base curricular sólida e permanente.

\subsection{COTAS COMO POLÍTICA PÚBLICA DE AÇÃO AFIRMATIVA}

Para sanar essa exclusão, o Prouni veio como uma política pública de ação afirmativa, onde o Estado desenvolve ações continuas visando à garantia dos direito sociais. Com isto, concede aos estudantes brasileiros, recém- formados no ensino médio da rede pública, bolsas de estudo integrais ou parciais (de 50\%) em curso de graduação e sequenciais de formação específica em instituições privadas de ensino superior. Em contrapartida, concede às instituições de ensino que aderem ao Programa Universidade Para Todos - Prouni - incentivos fiscais, como a isenção de alguns tributos.

\subsection{ACESSO ÀS INFORMAÇÕES E PROCESSO SELETIVO}

Os interessados em participar do Prouni, devem acessar o site eletrônico do $\mathrm{MEC}^{16}$, por meio do qual obterá todas as

\footnotetext{
16 Disponivel na internet via <http://siteprouni.mec.gov.br/como_funciona. php.> Acesso em 05/06/2017. 
informações quanto ao programa oferecido e aos requisitos necessários ao benefício.

Segundo o portal, fazem jus ao programa: os estudantes brasileiros que não tenham formação em curso superior; tenham cursado todo o período do ensino médio em escola da rede pública, ou tenha sido bolsista integral em escola da rede privada (ou ainda, cursado o ensino médio parcialmente em escola da rede pública e parcialmente em escola da rede privada, desde que tenha sido bolsista integral da própria escola privada); pessoa com deficiência. Caso o candidato seja atuante professor da educação básica da rede pública de ensino, ficará dispensado dos requisitos de renda, se estiver concorrendo exclusivamente à vaga nos cursos de licenciatura.

Cumulado com alguns dos requisitos anteriores, o candidato às bolsas integrais deve ter renda familiar bruta mensal de até um salário mínimo e meio por pessoa. Para as bolsas parciais de $50 \%$, a renda familiar bruta mensal duplica, ou seja, deve ser de até três salários mínimos por pessoa.

Ainda no mesmo endereço eletrônico, o processo seletivo do Prouni, realizado gratuitamente pela internet, duas vezes no ano, é composto por duas fases: processo regular (onde o candidato tenha participado do Exame Nacional do Ensino Médio - Enem - do ano imediatamente anterior e que tenha obtido, no mínimo, 450 pontos na média das notas das provas do Exame e nota acima de zero na redação); e processo de ocupação das bolsas remanescentes, referente às bolsas não utilizadas no decorrer do processo regular (para o caso em que o candidato seja professor da rede pública de ensino, no efetivo exercício do magistério da educação básica e integrando o quadro de pessoal permanente da instituição pública, para os cursos com grau de licenciatura destinados à formação do magistério da educação básica; ou tenha participado do Enem, a partir da edição de 2010, e que tenha obtido, em uma mesma edição do referido exame, média das notas nas provas igual ou superior a 450 pontos e nota superior a zero na redação). 
4.9 CONSIDERAÇÕES: FINANCIAMENTO PÚBLICO, MODELO PRIVADO LUCRATIVO

É notória a importância da formação acadêmica na vida de qualquer cidadão. A graduação proporciona maior discernimento, ascensão social, melhor competitividade e, consequentemente, maiores chances de inserção no mercado de trabalho. O país tende a se desenvolver mais a partir de novos profissionais capacitados em diversas áreas, como, por exemplo, professores (passarão a disseminar seus conhecimentos), cientistas (passam a trabalhar em diversos campos de pesquisa científica), médicos, engenheiros, publicitários, advogados etc.

No Brasil havia uma imensa desigualdade social que dificultava o acesso de estudantes do ensino médio, oriundos de escolas públicas, ao curso superior, em virtude das universidades públicas brasileiras não os absorverem até hoje. Essa realidade vem mudando desde a implementação de politicas públicas voltadas à educação superior.

O Prouni veio para mudar esse cenário, beneficiando em média cem mil estudantes de baixa renda, por ano, ao oportunizar condições de acesso às escolas superiores privadas, que de sua parte, se tornaram parceiras do governo. É a parceria governo versus modelo privado lucrativo.

Com isso, aposta-se numa sociedade mais justa, equânime, com acesso ao bem-estar e à maior inclusão social.

\section{HISTÓRIA DAS COTAS}

\subsection{CONCEITO HISTÓRICO}

Em 1960, foi implantada a Ação Afirmativa, nos Estados Unidos da América, com o intuito de proporcionar uma igualdade entre brancos e negros, com a finalidade de diminuir a desigualdade existente, em termos sociais, econômicos e culturais. O intuito desta ação foi proporcionar aos negros, uma igualdade em melhorar de vida, disponibi- 
lizando uma parcela de vagas nos ensinos superiores, consequentemente a possibilidade de competir igualmente no mercado de trabalho com brancos.

O instituto da ação afirmativa foi adotado em vários países, inclusive no Brasil, que foi tomando espaço a partir do ano de 2000. Os órgãos públicos e ensinos superiores começaram a aderir tal medida em vestibulares e concursos públicos.

Uma das pioneiras a adotar o instituto das ações afirmativas no Brasil foi a Universidade de Brasília, no ano de 2004. E desde então, outras universidades também começou a adotar a ação que passou a ser conhecida como sistema de cotas, onde não apenas sendo a cor o critério de admissibilidade, outros critérios começaram a surgir, por exemplo, vagas para indígena, pessoas com baixa renda e alunos que estudaram em escolas da rede pública.

Em junho de 2015, ocorreu um marco histórico, assim considerada a melhor Universidade do país, a USP (Universidade de São Paulo), adotou o sistema de cotas. Nesse sistema adotado pela universidade, são 13,4\% das vagas são destinados ao sistema de cotas, que entre eles estão o sistema do Sisu e os alunos de escola pública, e o restante das vagas será da forma tradicional por meio da Fuvest (sistema de vestibular próprio da USP, utilizado como forma de admissibilidade dos alunos no ensino superior).

\subsection{ASPECTOS SOCIAIS}

Diante da sociedade globalizada, onde o mercado de trabalho é um mar com tubarões, o sistema de cotas veio com a intenção de minimizar a diferença de oportunidades em relação aos alunos da rede pública, as cotas sócias e as raciais.

E nesse sentido, o sistema não visa privilegiar um aluno mais do que o outro, ao concorrer na vaga pelo sistema de cotas, há uma igualdade, onde o aluno estará concorrendo com os demais alunos que escolheram essa opção, de acor- 
do com a proporção de vagas oferecidas na instituição de ensino escolhida.

Desta forma, o sistema busca tratar os iguais de forma igual e os desiguais de forma desigual, buscando assim capacitar os jovens que se preenchem os requisitos de admissibilidade do sistema de cotas, para poderem concorrer de igual nível no mercado de trabalho.

Apesar do governo aparentemente demonstrar esta se preocupando com os jovens, com a criação do sistema de cotas, isto não aparenta ser a solução mais favorável para os jovens em relação à educação.

Em analise podemos considerar que o sistema de cotas, seria uma discriminação ao contrário, de forma que o estudante que se enquadraria no sistema de cotas, tanto o de rede pública, baixa renda ou pela cor, só conseguiu entrar na faculdade pelo programa e não pela sua real intelectualidade. De modo, essa afirmação está equivocada, o que na realidade acontece é a falta de um ensino de qualidade que o aluno de escola pública recebe, assim o mesmo não possui condições de concorrer com o aluno que sempre recebeu um ensino de qualidade.

Contudo, o governo tem o período de 10 (dez) anos, para acompanhar o sistema, e nesse período deveria está ocorrendo uma mudança no programa de educação, buscando melhorar seus ensinamentos desde os primeiros anos que a criança tem contato com a escola.

E ao observar as circunstâncias, após a criação do programa muitos dos estudantes que se enquadram no sistema de cotas, conseguiram ingressar no ensino superior, podendo assim se capacitar para o mercado de trabalho, todavia em contrapartida a educação infantil só tem piorado, de forma que se a educação estiver ruim, o sistema não poderá ser substituído, quando a sua real criação foi minimizar as diferenças, para que no futuro todos os alunos, independente de rede pública, renda ou cor, passam concorrer de igual modo. 
As cotas só garantiriam igualdade, se estes indivíduos apresentassem alguma dificuldade fisiológica intelectual que os colocassem em desvantagem às demais pessoas que concorrem a mesma vaga, o que não é verdade, já que negros e índios não são diferentes que brancos, asiáticos, pardos, anões, cristãos, judeus, paquistaneses ou seja lá o que for.

Não há qualquer fator que indique esta desvantagem no qual justificaria a implementação de cotas para esses individuos, a não ser uma desvantagem histórica e cheia de preconceitos, porém nada disso afeta o acesso destes indiviuos ao esino superior. Ao contrário, essa distinção apenas demonstra o preconceito que nossas leis ainda herdam.

\subsection{ASPECTOS JURÍDICOS}

Em 29 de agosto de 2012, foi promulgada a Lei $\mathrm{n}^{\circ} 12.711$, que regulamenta o sistema de cotas no território brasileiro. A Lei regulamenta todas as formas do sistema de cotas.

Dentre os sistemas de cotas, podemos dividi-los basicamente em três espécies, sendo que 50\% das vagas são reservadas para o sistema de costas, dentro dessas vagas são divididas para os alunos de rede pública, renda familiar e o sistema racial.

A Lei foi criada com o intuito de estimular os jovens que estudaram em escolas públicas, os com renda per capita baixa e os negros, a aprimorar seus conhecimentos, assim ingressando no ensino superior. Esse sistema de cotas reflete na ideia do governo tentar solucionar o problema em relação à desigualdade social existente no país que decorre do passado histórico como, por exemplo, a escravatura em relação à história dos negros no Brasil.

Sendo assim, o governo criou a Lei, como forma de obrigar as instituições de ensino a implementar em seu planejamento esse sistema, pois todas as universidade federais de ensino superior são obrigadas a obedecer esta lei. E en- 
tendemos que se fosse opcional, quase nenhuma instituição de ensino superior adotaria.

A Lei publicada em 2012 estabeleceu um prazo de até 04 (quatro) anos, para as instituições cumprirem totalmente o que foi proposto, como segue:

Art. 8o As instituições de que trata o art. 1o desta Lei deverão implementar, no mínimo, $25 \%$ (vinte e cinco por cento) da reserva de vagas prevista nesta Lei, a cada ano, e terão o prazo máximo de 4 (quatro) anos, a partir da data de sua publicação, para o cumprimento integral do disposto nesta Lei.

Com isso, cabe ao Poder Executivo, fiscalizar quanto ao cumprimento desta Lei.

Art. 7o O Poder Executivo promoverá, no prazo de 10 (dez) anos, a contar da publicação desta Lei, a revisão do programa especial para o acesso de estudantes pretos, pardos e indigenas, bem como daqueles que tenham cursado integralmente o ensino médio em escolas públicas, às instituições de educação superior.

A proposta do governo ao criar uma Lei que proporciona que os alunos que possuem uma carência, possam concorrer de igual forma com os outros alunos, visa estabelecer uma igualdade em relação à concorrência, capacitando assim aquele aluno de que ingressou por meio das cotas no ensino superior no mercado de trabalho.

Com isso a promulgação da Lei, traz como principal objetivo obrigar as instituições de ensino superior a adaptar-se ao sistema de cotas, para poder minimizar as marcas históricas trazidas pela desigualdade existente no país e buscando solucionar com este problema no futuro.

\section{CONCLUSÃO}

O direito à educação é sem dúvida uma preocupação do Estado, isto porque, seu papel é garantir aos cidadãos o 
bem comum' sendo assim temos a Constituição Federal, com lei suprema do país que irá regular todos os ordenamentos.

A garantia do direito à educação está prevista na Constituição Federal em seu art. $6^{\circ}$, possuindo um capítulo especifico no Capitulo III do Titulo VIII, disciplinado pelos artigos 205 a 214, onde estabelece de inicio, que a educação é um direito de todos, dever do estado e da família com a colaboração da sociedade, tendo por objetivo proporcionar o pleno desenvolvimento da pessoa, preparando-a para o exercício da cidadania e sua qualificação para o trabalho.

O cenário atual da educação pública no país, realmente encontra-se estagnado. O que se observa é que não há, por parte da massa popular, verdadeiro pleito por melhorias no setor educacional; há na verdade, um conformismo coletivo a respeito dos serviços educacionais prestados pelo Estado Brasileiro.

O Brasil ao longo dos anos de sua história tem acumulado uma divida social que muitos analistas consideram impagável. Ela consiste no preconceito racial que segregam partes da população brasileira. Uma sociedade na qual umas grandes parcelas das pessoas têm renda até um salário mínimo. Mas o governo tem sentido a necessidade de dar início a um processo que resgate parte desta dívida. A proposta de criação de cotas para o ingresso nos cursos superiores, destinados às ditas minorias (negros, índios), tem sido alegado como uma forma de resgate do direito de cidadania.

Logo, as cotas surgiram com o sentido de incluir os alunos de rede pública, o com baixa renda e o negro em cursos superiores. A partir da criação deste sistema implantado do governo, aumentou o número de alunos nesses critérios das cotas que ingressaram no ensino superior, sendo assim os mesmos tem iguais condições para competir no mercado de trabalho.

Todavia, não há qualquer justificativa plauzível para garantir cotas raciais, pois "raça" não é fator que gera des- 
vantagem de uma pessoa a outra, o que diferencia o negro do branco, o asiatico do indío é a cor de pele e nada mais.

Devemos abolir qualquer herança preconceituosa que ainda temos. Só assim podemos erradicar o preconceito e nos desenvolvermos como sociedade. Se assim não for, ainda estaremos estagnados com os mesmos habitos, com os mesmos problemas de desigualdade colhendo o mesmo fruto.

O ideal seria não ter nem cotas raciais e nem para pessoas de baixa renda. Cotas raciais pelos motivos que acabaos de expor. Pessoas de baixa renda só encontram-se em situação de vulnerabilidade e portanto precisam de cota, pois o ensino público no qual esta teve acesso não garante que esta tenha capacidades iguais de concorrencia a uma vaga em uma instituição de ensino superior. Com uma educação de qualidade à todos, acaba a necessidade de cotas.

\section{REFERENCIAS}

BARONI, J.M.B. Acesso ao Ensino Superior Público: realidade e alternativas. Tese (Doutorado) - Faculdade de Educação, Universidade de São Paulo, 2010. Disponivel na internet, por meio do site: <http://www. redeacaoafirmativa.ceao.ufba.br/uploads/usp_tese_2010_JMBaroni.pdf> Acesso em 07/09/2015.

BITTAR, M.; OLIVEIRA, J.F.; MOROSINI, M. (org.) Educação Superior no Brasil - 10 Anos pós-LDB - Coleção Inep 70 anos. Vol. 2, Brasília: INEP, 2008. Disponivel na internet, através do site: <http://www.publicacoes.inep. gov.br/portal/download/684> Acesso em 07/09/2015.

BRASIL. Constituição Federal. Disponível na internet, por meio do site: <http://www.planalto.gov.br/ccivil_03/Constituicao/Constituicao.htm> Acesso em 07/09/2015.

BRASIL. Estatuto da Criança e do Adolescente. Lei $\mathbf{N}^{\circ} \mathbf{8 . 0 6 9 / 9 0}$. Disponível na internet, por meio do site: <http://www.planalto.gov.br/ccivil_03/ LEIS/L8069.htm>. Acesso em 07/09/2015.

BRASIL. Plano Nacional de Educação - lei $\mathbf{n}^{\circ}$ 13.005/2014. Disponível na internet, por meio do site: <http://www.planalto.gov.br/CCIVIL_03/_Ato20112014/2014/Lei/L13005.htm.> Acesso em 07/09/2015.

CAPES. Coordenação de Aperfeiçoamento de Pessoal de Nivel Superior.

102 - Revista do Curso de Direito da Faculdade de Humanidades e Direito,

v. 14, n. 14, Edição Especial 2017 
Disponivel na internet, por meio do site: <http://www.capes.gov.br.> Acesso em $07 / 09 / 2015$.

CARDOSO, João Carlos. Comparações entre o ensino superior público e o privado. Disponivél na internet, por meio do site: <http://jornalggn.com. br/blog/luisnassif/comparacoes-entre-o-ensino-superior-publico-e-o-privado> Acesso em 21/01/2016.

CENTRO DE POLÍTICAS PÚBLICAS DO INSPER. Panorama educacional brasileiro. Disponivel na internet, por meio do site: <http://www.insper. edu.br/mwg-internal/de5fs23hu73ds / progress?id=QE0sG2tM4hq11sYy1M CdybcGe6-NJcdWJNqRDN5y54c.> Acesso em 09/10/2015.

CNE. Conselho Nacional de Educação. Disponível na internet, por meio do site: <http://portal.mec.gov.br/conselho-nacional-de-educacao/apresentacao> Acesso em 09/10/2015.

DEZEM, Guilherme Madeira; AGUIRRE, João Ricardo Brandão; FULLER, Paulo Henrique Aranda. Estatuto da Criança e do Adolescente. Vol. 14. Editora Revista dos Tribunais. 2009.

DOURADO, Flávia. Pesquisadora traça panorama do ensino público no Brasil. Disponivel na internet, por meio do site: <http://www.iea.usp.br/ noticia/pesquisadora-traca-panorama-do-ensino-publico-no-brasil.> Acesso em $11 / 12 / 2015$.

DURHAM, Eunice R. O ensino superior no Brasil: público e privado. Disponibilizado na internet via < http://nupps.usp.br/downloads/docs/dt0303. pdf>. Acesso em 21/01/2016.

EDUCAÇÃO NO BRASIL. Disponivel na Internet, por meio do site: <http:// www.brasilescola.com/educacao/educacao-no-brasil.htm.> Acesso em $11 / 12 / 2015$.

FIES. Financiamentos concedidos. Disponivel na internet, por meio do site: <http: / / fiesselecao.mec.gov.br/index.php?pagina=faq\#conhecendo.> Acesso em 10/09/2015.

FNDE. Fundo Nacional de Desenvolvimento e Educação. Disponível na internet, por meio do site: <http://www.fnde.gov.br> Acesso em 09/10/2015.

GOLDEMBERG, José. O repensar da educação no Brasil. Disponível na internet, por meio do site: <http://www.scielo.br/scielo.php?script=sci_artt ex\&pid=S0103-0141993000200004 > Acesso em 19/11/2015. 
INEP. Instituto Nacional de Estudos e Pesquisas Educacionais Anisio Teixeira. Disponivel na internet, por meio do site: <www.inep.gov.br.> Acesso em 13/09/2015

INES. Instituto Nacional de Educação de Surdos. Disponivel na internet, por meio do site: <http://www.ines.gov.br.> Acesso em 13/09/2015.

LEGISLAÇÃO de Direito Internacional. Saraiva. 2012.

MANTOAN EGLÉR, Maria Tereza. Inclusão promove a justiça. Disponível na internet, por meio do site: <http://revistaescola.abril.com.br/formacao/ maria-teresa-egler-mantoan-424431.shtml. > Acesso em 13/09/2015.

MEC. Ministério da Educação e Cultura. Disponivel na internet, por meio do site: <http://portal.mec.gov.br.> Acesso em 11/09/2015.

MINISTÉRIO DA EDUCAÇÃO. Acesso do estudante ao Fundo de Financiamento Estudantil. Disponivel na internet, por meio do site: <http:// fiesselecao.mec.gov.br.> Acesso em 14/12/2015.

MINISTÉRIO DA EDUCAÇÃO. Planejando a próxima década - 2014. Disponível na internet, por meio do site: <http://pne.mec.gov.br/images/pdf/ pne_conhecendo_20_metas.pdf.> Acesso em 23/10/2015.

MINISTÉRIO DA EDUCAÇÃO. Secretaria de Educação Superior, Fundo de Financiamento Estudantil - FIES - Prestação de Contas Ordinárias Anual, Relatório de Gestão do Exercício de 2014 - Abril de 2015. Disponivel na internet, por meio do site: <http://portal.mec.gov.br/index. php?option=com_content\&view $=$ article\&id=14949\&Itemid=1064. $>$ Acesso em 25/09/2015.

MOURA, Daiana Malheiros de. A Efetivação dos Direitos Fundamentais pelo Estado Fiscal: Função Social dos Tributos. 2011. Disponível na internet, por meio do site: <http://www.unisc.br/portal/images/stories/mestrado/ direito/dissertacoes/2011/daianamalheiros.pdf.> Acesso em 24/10/2015.

NERY, Maria Clara. Sociologia Contemporânea. IESDE. 2007.

O QUE É PISA. Disponivel na Internet por meio do site: <http://portal. inep.gov.br/pisa-programa-internacional-de-avaliacao-de-alunos $>$ Acesso em 03/10/2015.

PAINEL DE CONTROLE DO MEC. Disponível na internet, por meio do site: <http://painel.mec.gov.br.> Acesso em 04/10/2015. 
PAULO, Vicente e ALEXANDRINO, Marcelo. Direito Constitucional Descomplicado. Editora Saraiva. 2012.

PROUNI. Portal. Disponivel na internet, por meio do site: <http://siteprouni. mec.gov.br/como_funciona.php.> Acesso em 19/09/2015.

REVISTA Brasileira De Estudos Pedagógicos, MEC-INEP Brasília, Vol. 93, número 233, 2012. Disponivel na internet, por meio do site: <http://rbep. inep.gov.br/index.php/RBEP/article/viewFile/2638/1854.> Acesso em $11 / 09 / 2015$.

RISTOFF, D.; SEVEGNANI, P. (org.) Universidade e Compromisso Social: Brasilia, 25 e 26 de agosto de 2005. Coleção Educacional Superior em Debate. Vol. 4, Brasília: MEC/INEP, 2006. Disponivel na internet, por meio do site: <http://www.publicacoes.inep.gov.br/portal/download/481.> Acesso em 12/11/2015.

RODRIGUES, Zuleide Blanco. Os quatro pilares de uma e suas implicações na prática pedagógica. Disponível na internet, por meio do site: <http://www.educacional.com.br/articulistas / outrosEducacao_artigo. asp?artigo=artigo0056. $>$ Acesso em 12/11/2015.

VITAL, Diana Gonçalves; FARIA FILHO, Luciano Mendes. História da educação no Brasil: a constituição histórica do campo (1880-1970). Disponível na internet, por meio do site: <http://www.scielo.br/scielo.php?pid=S0102$-01882003000100003 \&$ script=sci_arttext. $>$ Acesso em 13/09/2015. 